\title{
Collective Psychology and Behavioral Characteristics of Patients with Inflammatory Bowel Disease: A Single Cohort Study
}

\author{
Ai Morimoto Hiroaki Ito \\ Kinshukai Infusion Clinic, Osaka, Japan
}

\section{Keywords}

Ulcerative colitis · Crohn's disease · Inflammatory bowel disease $\cdot$ Collective psychological characteristics

\begin{abstract}
Background: We previously treated patients with inflammatory bowel disease (IBD) using color therapy as part of projective psychotherapy and found differences in preferred colors selected in an imagined stressful situation between patients with ulcerative colitis (UC) and those with Crohn's disease (CD). In this study, we investigated differences in color selection among UC patients, CD patients, and healthy volunteers (HVs). More precisely, formal analysis using a projective technique was performed to evaluate their emotional characteristics when coping with stress, and egogram analysis was performed to investigate their collective psychological characteristics and behavioral characteristics as social selves. Methods: Eighty-three HVs, 70 UC patients, and $71 \mathrm{CD}$ patients were shown a sheet displaying images of bottles each containing 2 horizontally separated compartments filled in the same color or different colors. The preferred colors selected under imagined psychological stress (loneliness) were analyzed using a projection approach to investigate the emotional characteristics of the inner self. The To-
\end{abstract}

kyo University Egogram New Version II (TEG ${ }^{\circledR}$ II) was then used to analyze collective psychological characteristics and behavioral characteristics as social selves in the HV, UC, and CD groups. Results: Comparison of all 3 groups with the $x^{2}$ test showed that more participants chose calm colors in the CD group than in the HV and UC groups, while more participants chose stimulating colors in the UC group than in the CD group $(p<0.01)$. Analysis of TEG ${ }^{\oplus}$ II results with one-way analysis of variance and then with the Tukey-Kramer multiple comparison test revealed differences in collective psychological characteristics and behavioral characteristics in all 3 groups. Comparing scores for 5 types of ego states (Critical Parent, Nurturing Parent, Adult, Free Child, and Adapted Child) revealed that more participants in the $C D$ group had a low Critical Parent score than in the HV group ( $p<0.05$ ). More participants in the IBD group had a low Nurturing Parent score than in the HV group (CD vs. HV, $p<0.01$; UC vs. HV, $p<0.05)$. Significantly more participants in the UC group had a higher Adult score than in the HV or CD group (each $p<$ 0.01). Conclusions: The psychological characteristics of patients with IBD differ depending on the type of disease (i.e., CD vs. UC). Management based on such differences should be provided for patients with each disease type.

(c) 2020 The Author(s)

Published by S. Karger AG, Basel
(C) 2020 The Author(s)

Published by S. Karger AG, Basel

This is an Open Access article licensed under the Creative Commons Attribution-NonCommercial-4.0 International License (CC BY-NC) (http://www.karger.com/Services/OpenAccessLicense), applicable to the online version of the article only. Usage and distribution for commercial purposes requires written permission.
Hiroaki Ito

Gastroenterology, Kinshukai Infusion Clinic

Grand Front Osaka Tower B 9F, 3-1, Ofuka-cho, Kita-ku

Osaka 530-0011 (Japan)

office@ kic-clinic.jp 


\section{Introduction}

We previously treated patients with inflammatory bowel disease (IBD) with color therapy as part of projective psychotherapy using images of 111 bottles in different colors and revealed differences in motivating colors selected in an imagined stressful situation between patients with ulcerative colitis (UC) and those with Crohn's disease (CD). Given that the colors selected in the projective test are considered to represent emotional and unconscious aspects of the personality, we hypothesized that there are differences in personality characteristics between UC and CD patients.

The physiological effects of colors are widely known. For example, red increases blood pressure and heart rate, while blue decreases them $[1,2]$. However, studies on color preference are not standardized, and the results ob- tained are not consistent. Color preference is influenced by everyday factors, collective factors, and personal factors affecting individual as well as errors [3]. Sex differences in color preference also exist; for example, more women than men prefer pink and purple [4]. Also, the influence of cultural differences has been reported [5]. A projective color test conducted by Schaie and Heiss [6] in 1946 showed that the color most preferred by both men and women was red in the USA but green and blue, respectively, in Japan. Kawasome [7] reported in 1985 that the food color most preferred by men and women was orange in both Japan and the USA. Tsutsumi reported in 1988 that women did not like concepts associated with red and yellow as much as they liked them as colors [8]. Together these findings indicate that color preference is influenced by various factors including physiological, emotional, and cultural responses, sex, and how instructions are given before the test.

Table 1. Characteristics of participants

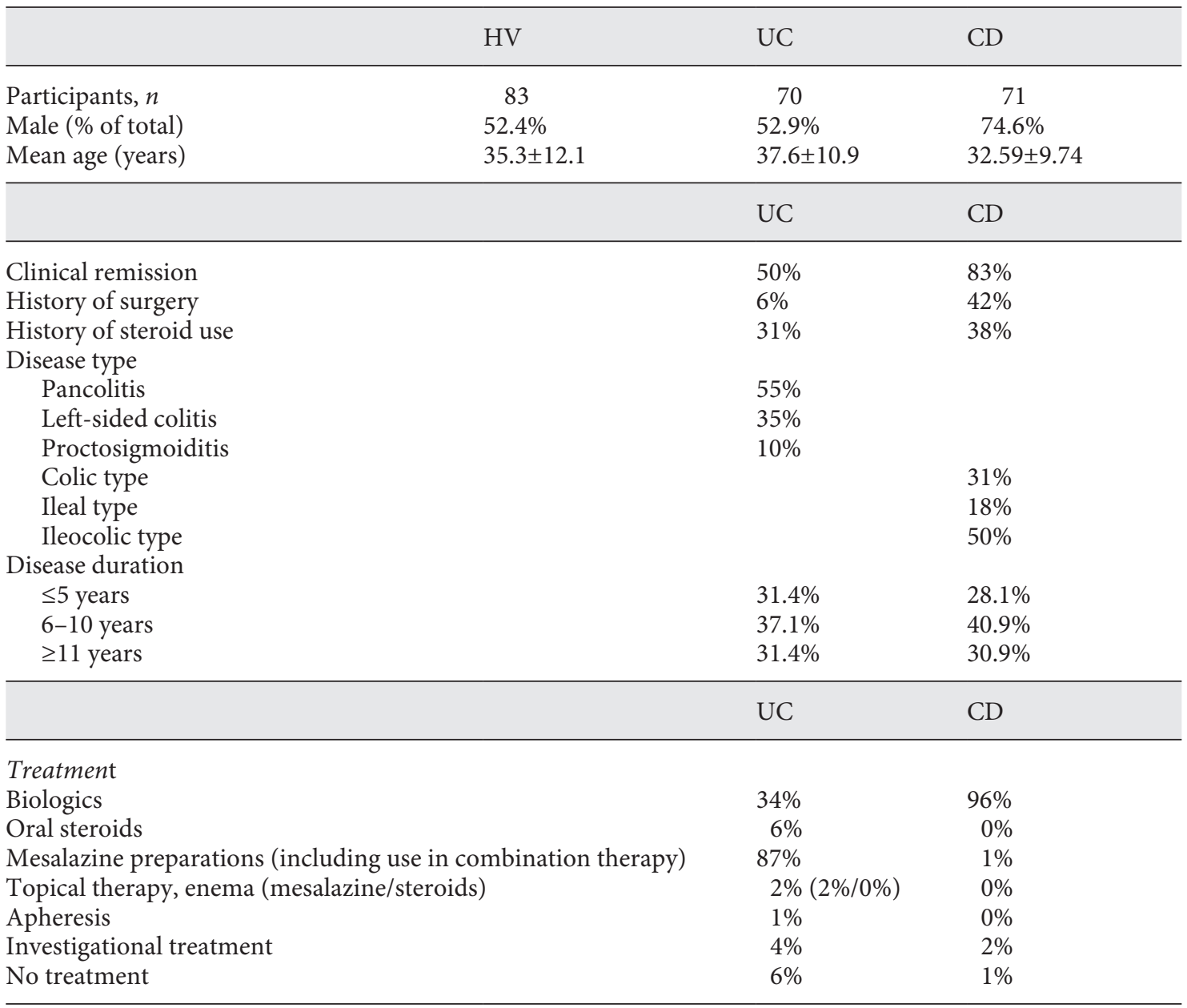

HV, healthy volunteer; CD, Crohn's disease; UC, ulcerative colitis. 
However, in a large-scale international survey, blue and red were the preferred colors irrespective of differences in region and culture [9], indicating these colors serve as more reliable objective indices than other colors.

Relationships between color preferences and personalities have been recently reported, with vivid colors (red and yellow) associated with aggression and extroversion and green and blue associated with social introversion $[10,11]$. The Rorschach test [12] and Color Pyramid Test [13] are personality tests that use a projective technique. They are widely used in the clinical setting and are based on the premise that colors influence emotions directly and that the resulting responses have meaning. For example, participants who respond to stimulating colors (e.g., red and yellow) are likely to be active and openly express their emotions, while those who respond to cold, dark colors (e.g., blue, green, and black) are likely to suppress their emotions [14].

In this study, we examined collective psychological characteristics and behavioral characteristics of UC patients and $\mathrm{CD}$ patients, using a projective technique (study 1) and a questionnaire method (study 2). In Study 1 , we performed a formal analysis of emotions and behavioral tendencies in each group, from the perspective that tendencies of inspiring and motivating colors selected in an imagined stressful situation are representative of personality characteristics reflecting the inner self. In study 2 , we investigated psychological and behavioral characteristics reflecting the social self, using an egogram, which is a more reliable objective scale than a projective technique. Also, based on the notion that any differences in psychological characteristics between UC and CD patients need to be considered in their management, we discuss the role of medical professionals in helping IBD patients continue treatment without causing them stress.

\section{Materials and Methods}

\section{Participants}

All participants were aged 18 years or older and were either (1) outpatients at Kinshukai Infusion Clinic with a definitive diagnosis of UC or CD made based on the diagnostic criteria from a "Survey and Research on Intractable Inflammatory Bowel Disorders" (Research Program on Rare and Intractable Diseases, Health, Labour and Welfare Sciences Research Grants) or (2) healthy volunteers (HVs) of various occupations, who were friends or family members of our staff or workers in the building where our clinic is located. Remission of UC was defined as a partial Mayo score of 0 or 1 and that of CD as Crohn's Disease Activity Index $<150$.

The UC and CD patients who participated in this study were randomly selected from among those patients aged $\geq 18$ years who visited our clinic from January 2015 to July 2017. All participants

Collective Psychology and Behavioral

Traits of Patients with IBD provided written informed consent. Table 1 shows participant characteristics.

\section{Study 1: Differences in the Preferred Colors Selected in the}

Imagined Stressful Situation among the Groups

We investigated which colors participants would select as motivating colors in the imagined stressful situation of feeling lonely. They were asked to choose 4 images of bottles with different color combinations, and we analyzed the categories of colors (cold, warm, neutral, and black-and-white) chosen by the 3 participant groups. Color preference was taken to reflect the tendencies of how participants inspire and motivate themselves, and we evaluated the emotional personality characteristics in each group. Participants were shown a sheet displaying images of 111 bottles, each of which had 2 horizontally separated compartments filled with the same color or different colors and randomly chosen. No text was shown on the sheet, but a separate question sheet was used to eliminate the influence of environmental factors [15]. The color combinations included complementary color pairs, combinations of achromatic color pairs, and combinations of the same hue but different brightness, and reverse orientation of these combinations. The highest chroma was used for each color, and the positions of individual color combinations were randomly determined. In total, 17 colors were used, and Table 2 shows their corresponding codes in the hue-tone Practical Color Coordinate System (PCCS) [16] and the frequencies of individual colors used in the sheet. Figure 1 shows an example of the sheet displaying images of bottles used.

To investigate preferred colors selected under imagined psychological stress, participants were given the following instructions: "Imagine that you have to spend the rest of your life all alone with no one else around. You can take 4 of these 111 bottles with

Table 2. Seventeen hues (according to the PCCS) used for the color selection test, and the frequency of each hue in the cumulative frequency of all 17 hues

\begin{tabular}{llc}
\hline Color & PCCS code & Frequency, \% \\
\hline Black & Bk & 4.5 \\
White & W & 8.6 \\
Purple & v20 & 8.2 \\
Light purple & lt20 & 2.7 \\
Midnight blue & v19 & 3.2 \\
Blue & v18 & 6.4 \\
Light blue & lt18 & 3.6 \\
Turquoise blue & b16 & 7.7 \\
Green & v12 & 9.5 \\
Light green & lt12 & 4.0 \\
Yellow & v8 & 4.5 \\
Light yellow & lt8 & 2.7 \\
Orange & v4 & 1.4 \\
Light orange & lt4 & 6.8 \\
Red & v2 & 7.3 \\
Pink & b2 & 13.2 \\
Magenta & v24 & 5.5 \\
\hline
\end{tabular}

PCCS, Practical Color Coordinate System. 
Table 3. Characteristics of the 5 ego states

\begin{tabular}{lll}
\hline & High score & Low score \\
\hline Critical Parent & $\begin{array}{l}\text { Has a strong belief and strict attitude toward self and others. } \\
\text { Sees value in keeping to rules. Expects others to have the } \\
\text { same sense of values. Cares about self. Can give a definite } \\
\text { negative answer to others }\end{array}$ & $\begin{array}{l}\text { Easygoing and not meticulous. Does not keep to } \\
\text { rules. Does not easily express own opinions. } \\
\text { Easily exploited, and not good at self-vindication }\end{array}$ \\
\hline Nurturing Parent & $\begin{array}{l}\text { Warm, kind, caring, and thoughtful. Helps others to } \\
\text { improve. Makes empathetic connections with others easily. } \\
\text { Can be overly caring and overpossessive }\end{array}$ & $\begin{array}{l}\text { Does not have close relationships with others. } \\
\text { Acts at own pace. Does not empathize. Is neither } \\
\text { obsessive nor sociable }\end{array}$ \\
\hline Adult & $\begin{array}{l}\text { Logical, rational, calm, and collected. Makes fair decisions } \\
\text { based on facts. Cold, impersonal, and machine-like. Is not } \\
\text { self-deprecating }\end{array}$ & $\begin{array}{l}\text { Humane, authentic, and people-pleasing. Relies } \\
\text { on subjective views. Not good at planning and has } \\
\text { incongruent thoughts and behaviors. Easily } \\
\text { confused }\end{array}$ \\
\hline Free Child & $\begin{array}{l}\text { Free, cheerful, curious, and likes challenges. Instinctive and } \\
\text { active. Emotional and impatient }\end{array}$ & $\begin{array}{l}\text { Quiet and not easily emotional. Not good at } \\
\text { enjoying self. Easily depressed and restrained }\end{array}$ \\
\hline Adapted Child & $\begin{array}{l}\text { Cooperative and straightforward. Impatient and can listen to } \\
\text { others'opinions. Tolerant of others. Cannot express own } \\
\text { opinions. Dependent }\end{array}$ & $\begin{array}{l}\text { Independent. Acts at own pace. Assertive and not } \\
\text { very cooperative. Does not compromise. Does not } \\
\text { listen to others }\end{array}$ \\
\hline
\end{tabular}

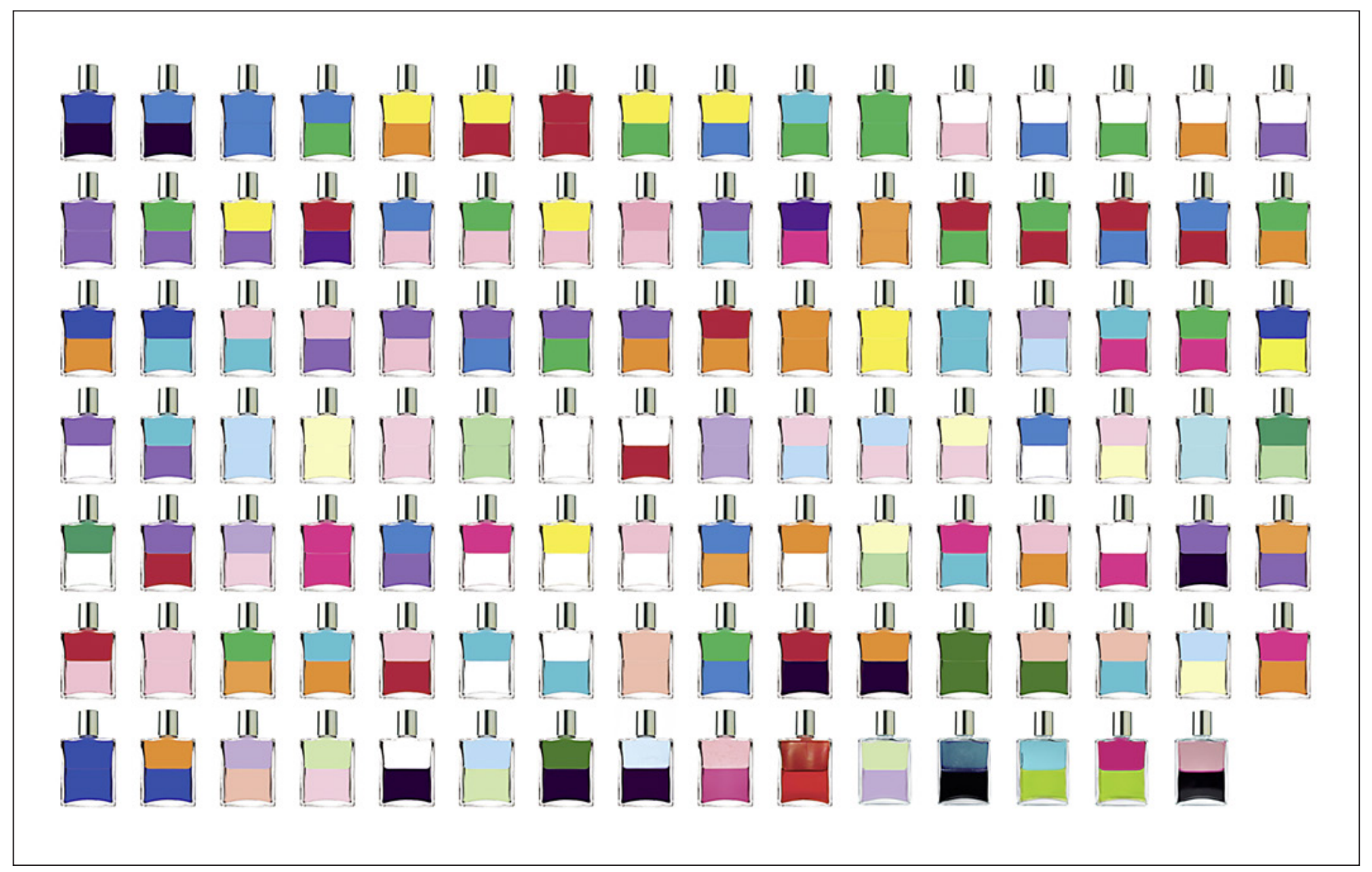

Fig. 1. Illustration of a sheet showing images of bottles with different color combinations used for the test. 
you but nothing else. Which bottles would you take? Please choose 4 bottles from here."

The colors used for the test were divided into 4 categories based on hue, but not brightness: stimulating colors (red, magenta, pink, orange, light orange, yellow, and light yellow); calming colors (midnight blue, blue, turquoise blue, and light blue); neutral colors (green, light green, purple, and light purple); and black and white [17]. A relevant color category was assigned 1 point when the corresponding color was used in a compartment of the selected bottle. For example, when a bottle with a combination of blue (top layer) and red (bottom layer) was chosen first, 1 point was added to the stimulating color category and another 1 point was added to the calming color category. When a bottle with a blue-blue combination was chosen second, 2 points were further added to the calming color category. Thus, a score of 8 points was given to each participant after selecting 4 bottles. The score of each color category was then calculated for each group for further analysis.

\section{Study 2: Differences in Ego State and Behavioral}

\section{Characteristics among the Groups}

We used the Tokyo University Egogram New Version II (new ver. TEG ${ }^{\circledR}$ II) developed by the TEG Study Group at the Department of Psychosomatic Medicine, The University of Tokyo Hospital [18]. The data obtained were analyzed to reveal the ego state and behavioral characteristics in each group. The new version $\mathrm{TEG}^{\circledR} \mathrm{II}$, developed based on transactional analysis proposed by the American psychiatrist Berne Eric [19], is a 53-item personality test in which the ego state is defined as a system integrating emotions, thoughts, and a related set of associated behavior patterns. It is based on the notion that everyone has Parent, Adult, and Child ego states. The Parent state is further divided into the Critical Parent state and the Nurturing Parent state, and the Child state is subdivided into the Free Child state and the Adapted Child state. Table 3 summarizes the characteristics of these ego states.

The egogram is a psychological test used to understand personality traits and behavioral characteristics, the results of which are usually displayed as bar charts. Because men tend to have higher scores for the Critical Parent, Adult, and Adapted Child states but lower scores for the Nurturing Parent and Free Child states than women, standardized percentile values have been established. We sought to eliminate the influence of sex differences on differences in personality traits and behavioral characteristics among the HV group $(n=83)$, UC group, and CD group $(n=71)$, so we compared the distribution of participants across the low- (0-25), mid- (26$75)$, and high- (76-100) percentile values for the 5 ego states, instead of comparing simple mean scores. Also, we sought to clarify which behavior items among the 53 questionnaire items differed among the groups.

\section{Results}

\section{Participants}

In total, 70 UC patients (mean age, $37.57 \pm 10.93$ years; men, 52.9\%), $71 \mathrm{CD}$ patients (mean age, $32.59 \pm 9.74$ years; men, $74.6 \%$ ), and $83 \mathrm{HVs}$ (mean age, $35.3 \pm 12.14$
Table 4. Comparison of selected colors between the groups: results of the $\chi^{2}$ test

\begin{tabular}{lllll}
\hline $\begin{array}{l}\text { Participants, } n / \\
\text { score }\end{array}$ & $\begin{array}{l}\text { Stimulating } \\
\text { colors }^{\text {a }}\end{array}$ & $\begin{array}{l}\text { Calming } \\
\text { colors }^{\text {a }}\end{array}$ & $\begin{array}{l}\text { Neutral } \\
\text { colors }\end{array}$ & $\begin{array}{l}\text { Black and } \\
\text { white }\end{array}$ \\
\hline HV $(n=82)$ & 289 & 178 & 111 & 78 \\
CD $(n=72)$ & 219 & 190 & 98 & 61 \\
UC $(n=69)$ & 250 & 124 & 104 & 74 \\
\hline
\end{tabular}

Intergroup comparison of scores for each color category. A color category was assigned 1 point when the corresponding color was used in a compartment of the selected bottle. Each participant scored 8 points by selecting 4 bottles. $\mathrm{HV}$, healthy volunteer; $\mathrm{CD}$, Crohn's disease; UC, ulcerative colitis. ${ }^{\mathrm{a}} p<0.01$.

Table 5. Comparison of scores for individual color categories between 2 groups: results of the $\chi^{2}$ test ( $p$ values)

\begin{tabular}{lllll}
\hline & $\begin{array}{l}\text { Stimulating Calming } \\
\text { colors }\end{array}$ & $\begin{array}{l}\text { Neutral } \\
\text { colors }\end{array}$ & $\begin{array}{l}\text { Black and } \\
\text { white }\end{array}$ \\
\hline HV versus CD & 0.051 & $0.016^{\mathrm{a}}$ & 0.877 & 0.526 \\
$\mathrm{HV}$ versus UC & 0.667 & 0.061 & 0.384 & 0.428 \\
$\mathrm{HV}$ versus IBD & 0.370 & 0.681 & 0.551 & 0.918 \\
$\mathrm{CD}$ versus UC & $0.022^{\mathrm{a}}$ & $4.266 \mathrm{E}-05^{\mathrm{a}}$ & 0.489 & 0.170 \\
\hline
\end{tabular}

Differences in total scores for individual categories of colors selected between 2 groups. HV, healthy volunteer; CD, Crohn's disease; UC, ulcerative colitis. ${ }^{\mathrm{a}} p<0.01$.

years; proportion of men, $52.4 \%)$ participated. The proportion of patients in clinical remission was $50.0 \%$ in the UC group and $83.3 \%$ in the CD group (Table 1 ).

\section{Study 1: Differences in Preferred Colors Selected}

Total scores for the individual color categories were compared between the groups using the $\chi^{2}$ test. Significant differences were found in the scores for the stimulating color category and the calming color category (both $p<0.01$ ), but not for the neutral or black-and-white color category (Table 4). Multiple comparison showed that more participants in the $\mathrm{CD}$ group chose calming colors than in the HV and UC groups, and the difference between the CD and UC groups was larger than that between the $\mathrm{CD}$ and $\mathrm{HV}$ groups. There were no differences in color selection between the UC and HV groups. A higher proportion of participants in the $\mathrm{CD}$ group chose calming colors than in the HV and UC groups. There were no differences between the HVs and IBD patients. 
Taken together, the preferred colors selected were markedly different between the CD and UC groups but not between the HV and CD groups or between the HV and UC groups (Table 5).

\section{Study 2: Differences in Ego Status and Behavioral Characteristics}

Analysis of the egogram results with one-way ANOVA and then with the Tukey-Kramer multiple comparison test revealed that score distributions in the Critical Parent, Nurturing Parent, and Adult states were significantly different between the groups (Table 6). Specifically, more participants had a low Critical Parent score in the CD group than in the HV group $(p=0.044)$. There was no significant difference in the Critical Parent state between the UC and HV groups or between the UC and CD groups. A low Critical Parent score indicates a friendly, undemanding, nonaggressive, and noncritical personality but also indicates a poor sense of responsibility and ethics. Thus, those with a low Critical Parent score are unlikely to be good at maintaining discipline, keeping to instructions, or following rules.

More IBD patients had a low Nurturing Parent score than HVs (CD vs. HV, $p=0.010$; UC vs. HV, $p=0.016$ ). There were no significant differences between the $\mathrm{CD}$ and UC groups. A low Nurturing Parent score indicates indifference and closed behavior characteristics, and participants with such a score are unlikely to cause unnecessary interference to others and likely to act at their own pace without forming overly close relationships.

Significantly more participants had a high Adult score in the UC group than in the HV and CD groups ( $p=0.009$ and $p=0.006$, respectively). There was no significant difference between the HV and CD groups. A high Adult score indicates ability to make logical and rational decisions and to behave accordingly with little emotional interference. Those with a high Adult score are likely to be efficient and productive, but those with an excessively strong Adult score are often machine-like, lack humanity, and are self-absorbed [10,20].

Next, we analyzed the responses of the 53 individual items of the egogram using one-way ANOVA and the Tukey-Kramer multiple comparison test to reveal which behavioral characteristics differed among the groups (Table 7). There were significant differences in responses to items associated with the Critical Parent, Nurturing Parent, Adult, and Free Child states.

For the CD group, compared with the HV group, fewer participants responded affirmatively to feeling a sense of responsibility (which is an item associated with the

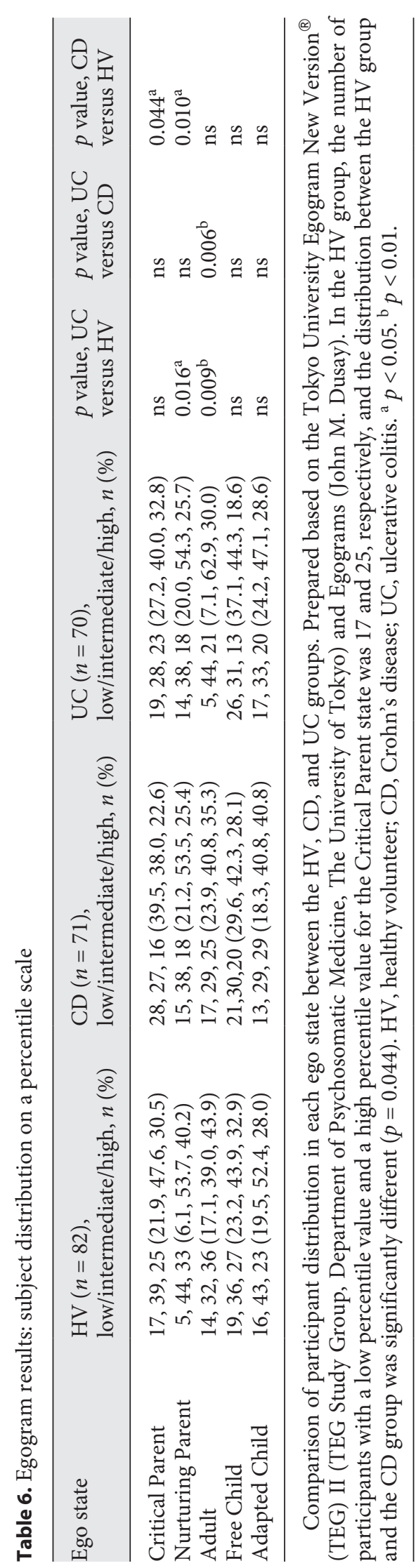


Table 7. Egogram items associated with individual ego states

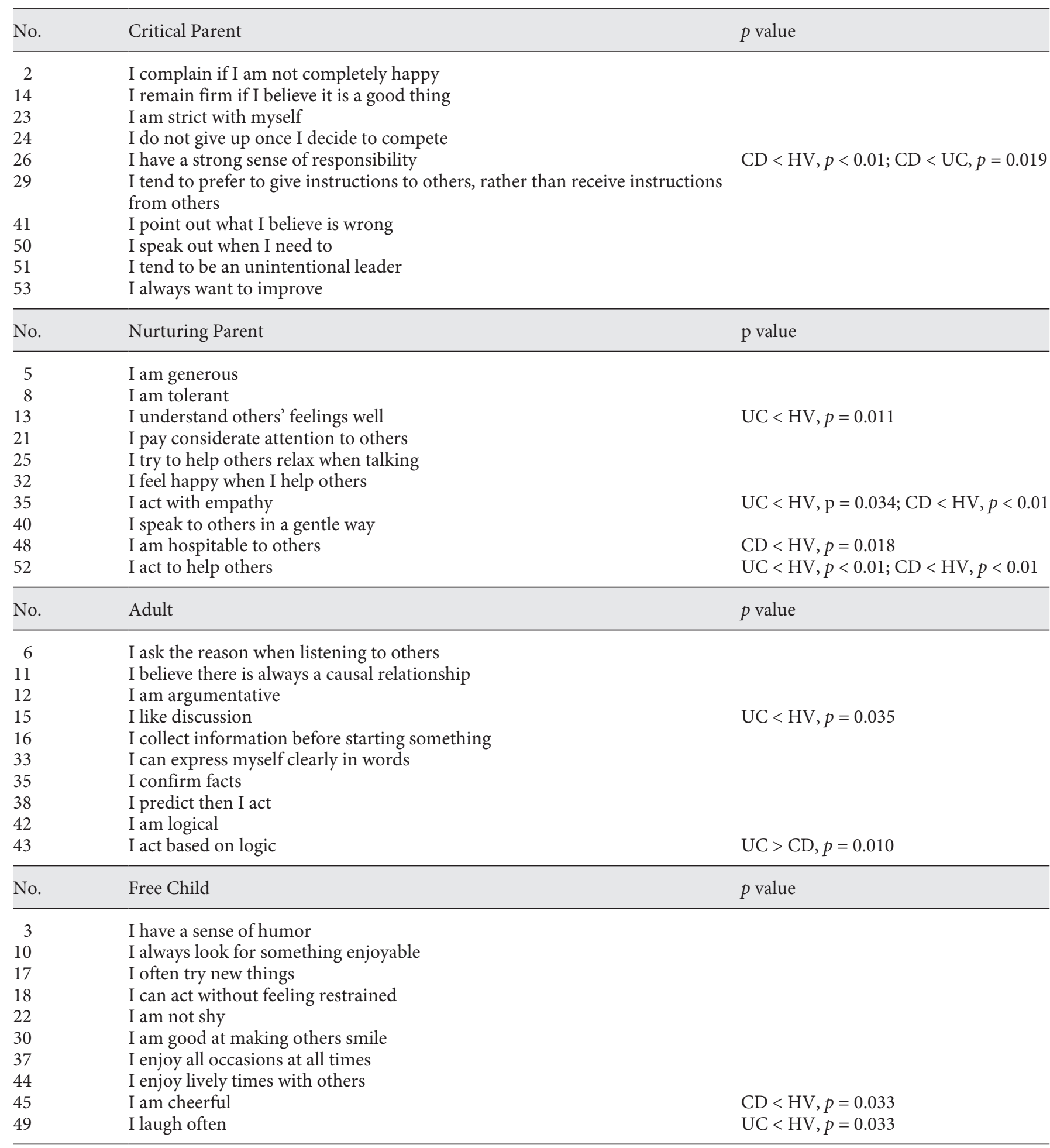


Table 7 (continued)

\begin{tabular}{rll}
\hline No. & Adapted Child & p values \\
\hline 1 & I am easily influenced by others' opinions & \\
4 & I care about what others think of me & \\
7 & I am often self-conscious about what people think when I do something & No significant differences in any item \\
9 & I often change my mind & \\
19 & I tend to get instructions from others & \\
28 & I often do what others tell me to & \\
31 & I am sensitive to others' moods & \\
36 & I worry about what others say & \\
46 & I am indecisive & I am not good at making decisions \\
\hline
\end{tabular}

Critical Parent state). Also, fewer responded affirmatively to acting with empathy, being hospitable to others, and acting to help others (items associated with the Nurturing Parent state). Given that these items of the Nurturing Parent state represent an attitude of active involvement with others, the results indicate that CD patients were hesitant about being involved with others compared with HVs. There were no differences in items associated with the Nurturing Parent state between the CD and UC groups. Fewer participants in the CD group reported behaving logically (associated with the Adult state) compared with the UC group. A sense of responsibility and logical behavior represent the resolute attitude of adults, and more CD patients than UC patients were not good at being assertive or maintaining roles. Fewer participants in the CD group reported being cheerful (associated with the Free Child state) compared with the HV group. There were no significant differences in items related to the Adapted Child state between the CD and UC groups and/or between the $\mathrm{CD}$ and HV groups.

For the UC group compared with the other groups, there were significant differences in items related to the Nurturing Parent, Adult, and Free Child states. Compared with the HV group, fewer participants in the UC group reported understanding the feelings of others well, acting with empathy, and acting to help others (items associated with the Nurturing Parent state). Fewer participants reported enjoying discussions (associated with the Adult state); this trend was similar to that in the CD group. Compared with the CD group, more participants in the UC group reported behaving logically (associated with the Adult state). Compared with the HV group, fewer participants reported laughing often (associated with the Free Child state). These results indicate that UC patients, like CD patients, were not as active communica- tors as HVs were, but UC patients were more likely than $\mathrm{CD}$ patients to behave logically without being influenced by the feelings of others.

\section{Discussion}

This study showed that, in an imagined stressful situation, UC patients tended to select stimulating colors more than $\mathrm{CD}$ patients, and CD patients tended to select calming colors more than HVs and UC patients. UC patients appeared to be motivated by warm and vibrant colors, suggesting a tendency to be active and openly express their emotions. In contrast, CD patients appeared to be motivated by calming colors, suggesting a tendency to be calm and reserved and to not easily express their emotions. Given the higher proportion of men in the CD group than in the HV and UC groups and that men prefer blue more than women [4], the possible influence of sex differences should be taken into consideration. However, the difference in the frequency of selecting calming colors between the CD and UC groups $(p<0.001)$ may be large even with the influence of sex differences, based on the results where the slightly lower preference for calming colors in the UC group than in the HV group $(p=0.061)$ where there were similar proportions of men. Other participant characteristics that possibly influenced the preference of stimulating colors in the UC group were remission rate (50\% in the UC group vs. $83 \%$ in the CD group) and physiological factors of the disease. Conversely, severity of disease in the $\mathrm{CD}$ group, indicated by medication (oral mesalazine alone: $46 \%$ in the UC group vs. $1 \%$ in the CD group; biologics: $96 \%$ in the CD group), may have influenced the preference for calming colors in the CD group. Given that color preference, which is considered 
to be a projection of deep psychological aspects, is influenced by various factors and that the groups were not matched for these factors in this study, close examination using carefully matched groups (e.g., by sex and disease severity) is warranted in future studies.

We performed egogram analysis using a percentile scale, taking into account sex bias, and found that a low Nurturing Parent score was a common feature among IBD patients. This state represents an attitude of acceptance of self and others, and a low score represents a closed attitude. Thus, participants with a low Nurturing Parent score tended not to have close relationships with others and were likely to act at their own pace. In this study, more than half of the UC patients were not in remission, and many CD patients were likely to have severe CD even though they had achieved remission (previous history of surgery: $42 \%$; history of biologics use: $96 \%$ ). IBD is not readily visible to others, and patients are likely to resolve their physical and psychological problems by themselves without discussing it with others. It is difficult to get empathy and understanding even among IBD patients because symptoms vary among individuals, and thus IBD patients tend to have their own perspective of the world and their own independent lifestyle. This background might have influenced the results of our study. A study in 2015 showed that adverse childhood experiences, especially history of childhood sexual abuse in women, was associated with anxiety disorder and chronic abdominal pain in IBD patients [21], and having a positive outlook on interpersonal relationships will be even more difficult among patients with such adverse childhood experiences.

Analysis of egogram results also showed differences between the CD and UC groups. The low Critical Parent score in the CD group indicated that, compared with HVs, CD patients are likely to be friendly toward others and to keep a low profile. Compared with UC patients, CD patients are more likely to be reserved, friendly, not good at pleasing themselves in a logical manner, being overly strict about rules, and giving up on problems rather than solving them. Meanwhile, the Adult score was higher in the UC group than in the HV and CD groups in this study. Individuals with a high Adult score tend to be logical and efficient, and their attitudes toward others tend to be firm and not overly empathic. Compared with CD patients, UC patients are more likely to be seen as difficult, but they have good adherence once they understand the treatment logically.

This raises a question as to the kind of support needed by IBD patients who are not actively interacting with others. IBD patients are reported to have fewer physical

Collective Psychology and Behavioral Traits of Patients with IBD symptoms when they are more self-involved and are more satisfied with social support [22]. Improving the quality of IBD treatment will essentially require patients to have an open attitude toward healthcare professionals and others around them, although they tend to be distant. Support from healthcare professionals should include taking time to listen to the patients' thoughts and past experiences. Trying to understand the patients' values and lifestyle, rather than just giving them instructions, will communicate to them that they are accepted. When patients feel they are accepted by treatment providers, they can be trusting and more positive about treatment, and consequently opportunities to be involved in the society will gradually increase.

This study showed a lower Critical Parent score in the CD group than in the UC group, in good agreement with more severe anxiety and depression among CD patients than UC patients previously reported [23], suggesting that $\mathrm{CD}$ patients tend to avoid arguments and deal with problems internally rather than externally. When treating these patients, we should remember that their "OK" may actually be "not OK." Also, in the busy clinical setting, they may be hesitant to disclose important information. Routine use of a questionnaire and quality of life psychological inventory could help treatment provision to $C D$ patients who are particularly hesitant about communicating with others.

Better therapeutic provision for UC patients relies on having a high Adult score, as shown in this study. Boye et al. [24] reported that stress management therapy improved quality of life in UC patients but not in CD patients. Our study using a projective technique indicated that UC patients are not necessarily friendly but are active, and compared with CD patients, they are more likely to behave positively, logically, and efficiently. Psychotherapy involves verbalization of thoughts and logical understanding of the condition, so logical thinking is required to achieve improvement. The present findings suggest that psychotherapy could be particularly effective for UC patients. They are likely to be convinced when a causal relationship is thoroughly explained to them and clear information is provided about medications and treatment regimens. Providing detailed and practical information, for example, explaining what foods are permissible rather than saying that they "can eat normally" and explaining the amount of exercise needed (e.g., the number of steps or duration of exercise), will convince UC patients, helping them become more cooperative.

Our participants were patients at our clinic who could spare the time to participate and were recruited by our 
nurses. The sex ratio of the total participant population was representative of the Japanese population (i.e., more men with CD than women). This study could not investigate differences due to sex, disease status (remission vs. flare up), or disease severity. We used a projective technique with images of colored bottles, but few previous studies have used the same approach. Differences in preferred colors between men and women without imagined stress have been reported, but not between men and women with imagined stress. Further study using matched participant groups is anticipated.

\section{Conclusion}

We hypothesized that personality traits differ between UC patients and CD patients based on our previous findings in psychotherapy. Here, we used a projective technique that involved selecting images of bottles with preferred color combinations and found that preferred colors were different between UC patients and CD patients. Study 1 using a projective technique and study 2 using a psychological test both confirmed differences in personality characteristics between the UC and CD populations. Although individual differences will exist in each population, it is pertinent to note that CD patients who are smiling and friendly may in fact be having difficulty expressing pain or that UC patients who are not so friendly and may even be aggressive may in fact have unsolved irritation and anxiety. Such knowledge can help healthcare professionals to detect patients' distress signals.

\section{Acknowledgement}

We thank Ms. Kayoko Sakagami for her support in data collection.

\section{Statement of Ethics}

This study was approved by the Ethics Committee of Kinshukai Infusion Clinic (Approval No. 2014-10) and was conducted in accordance with the Declaration of Helsinki. All participants received the explanation that personal information would not be disclosed and there would be no disadvantage to them if they declined to participate in the study, and written consent was then obtained. Participants were informed about the test results in writing.

\section{Conflict of Interest Statement}

A.M. received lecture fees from Janssen Pharmaceutical KK, Mitsubishi Tanabe Pharma KK, and Takeda Pharmaceutical KK. H.I. received lecture fees from AbbVie GK, Janssen Pharmaceutical KK, Pfizer KK, Mitsubishi Tanabe Pharma KK, Mochida Pharmaceutical KK, Nippon Kayaku KK, Zeria Pharmaceutical KK, and Takeda Pharmaceutical KK.

\section{Funding Sources}

This research received no specific grant from any funding agency in the public, commercial, or not-for-profit sectors.

\section{Author Contributions}

A.M. and H.I. contributed to the conception and design of the study. A.M. also contributed to data collection, data analysis, and drafting of the article. H.I. also contributed to revision of the article. Both A.M. and H.I. approved the final version of the manuscript.

\section{References}

1 Kodama T, Morita K, Doi R. Effects of the color environments on the human cognitive function. Jpn J Clin Neurophys. 2007;35(1): $1-9$.

2 Itagaki E, Sakuragi M, Takakuda A. Relation of the five senses and blood pressure (III) stimulation to eyesight (influence of color). Ann Rep Kyoritsu Coll Phar. 1998;43:29-35.

3 Ohmi G. Colors and emotions. In: Japan Color Research Institute, editor. Color encyclopedia. Tokyo: Maruzen KK; 2005. p. 124-4.

4 Hurlbert AC, Ling Y. Biological components of sex difference in color preference. Curr Biol. 2007 Aug; 17(16):R623-5.
5 Bonnardel V, Beniwal S, Dubey N, Pande M, Bimler D. Gender difference in color preference across cultures: an archetypal pattern modulated by a female cultural stereotype. Color Res Appl. 2018 Apr;43(2):209-23.

6 Schaie KW, Heiss R. Color and personality. A manual for the Color Pyramid Test (Farbpyramiden-Test). New York: Grune \& Stratton; 1964.

7 Kawasome S. Changes in preferred food colors by age and sex. J Home Econ Jpn. 1987; 38(1):23-31.

8 Chijiwa $\mathrm{H}$. Illustrated dictionary of colors and associated emotions in the world. Tokyo: Kawade Shobo Shinsha; 1999.
9 Tsutsumi M. Color preference and color word preference. Mem Fac Educ, Shimane Univ (Humanity, Soc Sci). 1988;22(1):45-51.

10 Matsuda H, Natori K. The relationship between color preferences and personality traits: consideration from the emotional meaning of color. J Color Sci Assoc Jpn. 2019; 43(2):69-80

11 Oishi Y, Ishimoto G. Association of color preference and personality characteristics in the student who learns health and welfare. J Color Sci Assoc Jpn. 2019;43(3):169-71.

12 Takahashi M, Kitamura Y. The Rorschach diagnosis test I II. Tokyo: Saiensu-sha; 1981. 
13 Muneuchi A, Muneuchi M. Color pyramid test introduction. Tokyo: Shoshi-saiko; 2012.

14 Yamawaki K. Everything about color psychology. Tokyo: Natsumesha; 2013.

15 Muto E. A complete guide to aura-soma (new ver.). Tokyo: Shufunotomo-sha; 2012.

16 Advance Forward True Colors. Color coordination proficiency test, official text for the first level. Tokyo: Association of Color Official Approval; 2010.

17 Tokyo Chamber of Commerce and Industry. Color coordinator Proficiency test, official text for the second level (ver. 3): Color coordination. Tokyo: Chuokeizai-sha; 2012.
18 TEG Study Group of the Department of Psychosomatic Medicine, The University of Tokyo, editor. Tokyo University Egogram New Ver. II. Practical manual. Tokyo: Kanekoshobo; 2013.

19 Shinzato R, Mizuno M, Katsura T, Sugita M. Transactional analysis and egogram. Tokyo: Team Iryo; 1986.

20 Fukazawa K, Takataya K, Sato T. Physiologi$\mathrm{cal}$ and emotional response of healthy adults to colors. Yamanashi Nurs J. 2009;8(1):23-7.

21 Fuller-Thomson E, Lateef R, Sulman J. Robust association between inflammatory bowel disease and generalized anxiety disorder: findings from a nationally representative $\mathrm{Ca}$ nadian study. Inflamm Bowel Dis. 2015 Oct; 21(10):2341-8.
22 Shimura M. Psychosocial considerations for patients with inflammatory bowel disease: preliminary study in California. Jpn J Psychosom Med. 1997;37(7):491-501.

23 Mikocka-Walus A, Knowles SR, Keefer L, Graff L. Controversies revisited: a systematic review of the comorbidity of depression and anxiety with inflammatory bowel diseases. Inflamm Bowel Dis. 2016 Mar;22(3):752-62.

24 Boye B, Lundin KEA, Jantschek G, Leganger S, Mokleby K, Tagen T, et al. INSPIRE study: dose stress management improve the course of inflammatory bowel disease and diseasespecific quality of life in distressed patients with ulcerative colitis or Crohn's disease? A randomized controlled trial. Inflamm Bowel Dis. 2011. Sep;17(9):1863-73. 